Erratum

\title{
Erratum to "Combined Acceleration Methods for Solid Rocket Motor Grain Burnback Simulation Based on the Level Set Method"
}

\author{
Ran Wei $(\mathbb{D}$, Futing Bao $(\mathbb{D}$, Yang Liu $(\mathbb{D}$, and Weihua Hui $(\mathbb{D})$ \\ Science and Technology on Combustion Internal Flow and Thermal-Structure Laboratory, School of Astronautics, Northwestern \\ Polytechnical University, Xi'an 710072, China \\ Correspondence should be addressed to Weihua Hui; zhongyuancao@163.com \\ Received 19 May 2018; Accepted 30 May 2018; Published 28 June 2018 \\ Copyright ( 92018 Ran Wei et al. This is an open access article distributed under the Creative Commons Attribution License, which \\ permits unrestricted use, distribution, and reproduction in any medium, provided the original work is properly cited.
}

In the article titled "Combined Acceleration Methods for Solid Rocket Motor Grain Burnback Simulation Based on the Level Set Method" [1], Dr. Ran Wei was incorrectly listed as the corresponding author. The corresponding author is Dr. Weihua Hui.

\section{References}

[1] R. Wei, F. Bao, Y. Liu, and W. Hui, "Combined acceleration methods for solid rocket motor grain burnback simulation based on the level set method," International Journal of Aerospace Engineering, vol. 2018, Article ID 4827810, 12 pages, 2018. 


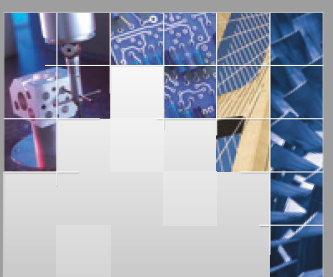

\section{Enfincering}
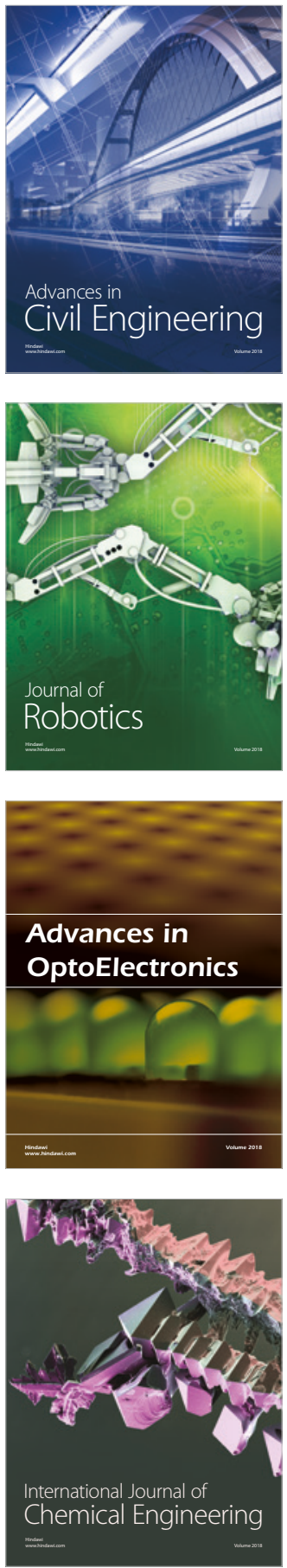

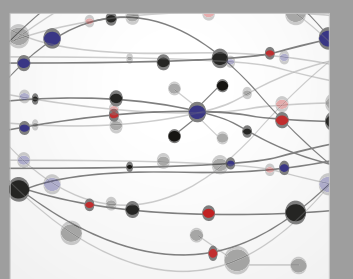

\section{Rotating \\ Machinery}

The Scientific World Journal

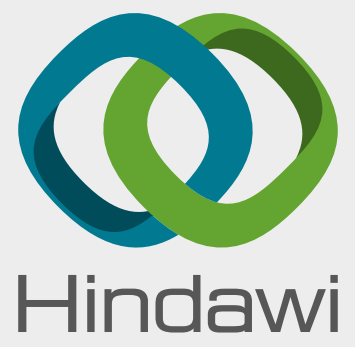

Submit your manuscripts at

www.hindawi.com
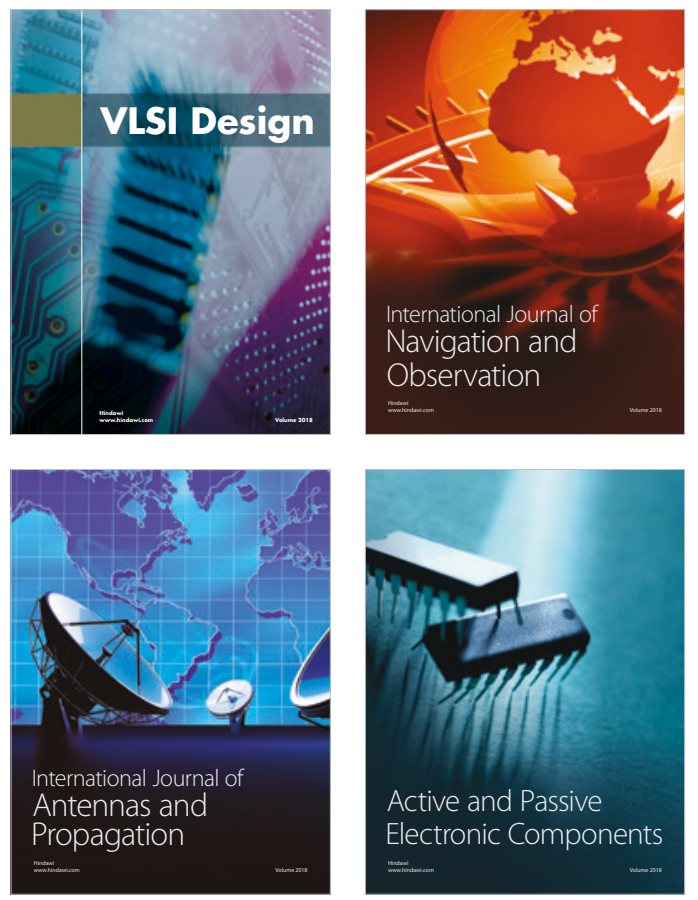
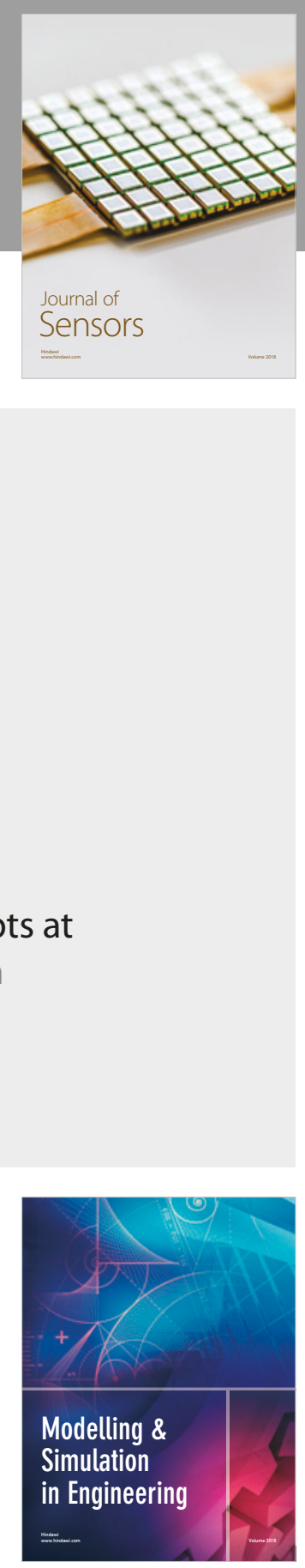

\section{Advances \\ Multimedia}
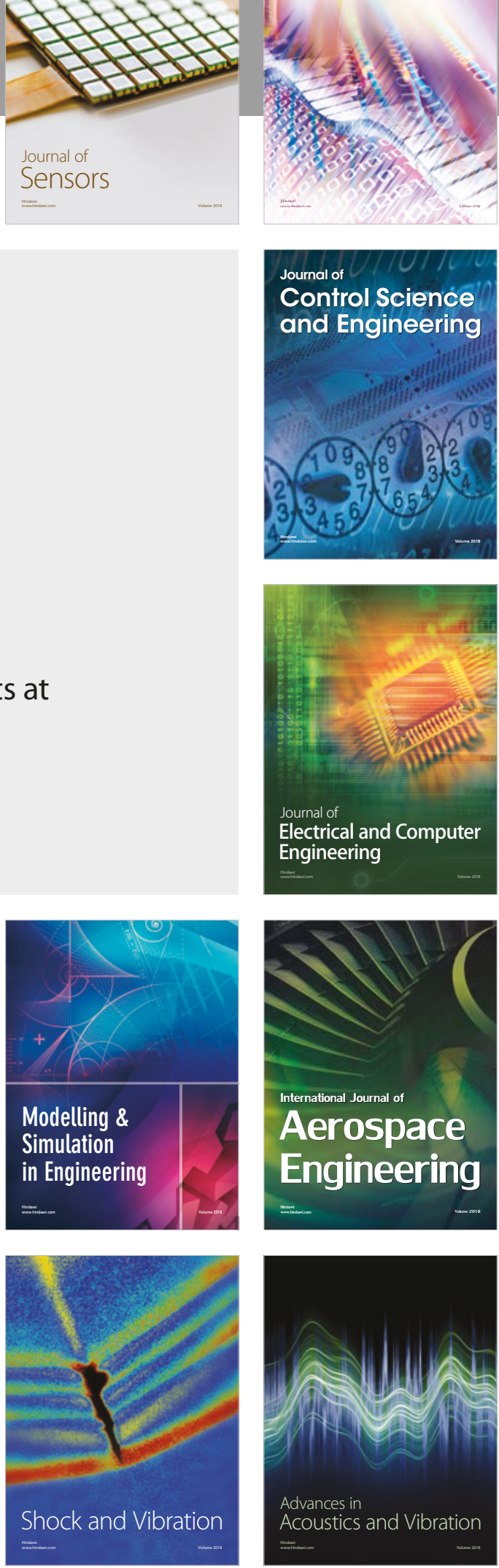